NBER WORKING PAPER SERIES

\title{
GLOBAL COMPARATIVES STATICS IN GENERAL EQUILIBRIUM: MODEL BUILDING FROM THEORETICAL FOUNDATIONS
}

\author{
James R. Markusen \\ Working Paper 27219 \\ http://www.nber.org/papers/w27219
NATIONAL BUREAU OF ECONOMIC RESEARCH
1050 Massachusetts Avenue
Cambridge, MA 02138
May 2020

This paper is a re-focused and re-oriented version of a paper prepared for a special issue of the International Journal of Economic Theory in honor of Ronald W. Jones, entitled "Ronald Jones duality analysis as a foundation for applied general-equilibrium modeling" The author thanks Alan Woodland and Thomas Rutherford for suggestions and perspectives. Not only for helpful comments and suggestions on this paper, but for making essential contributions to the theory underlying the paper. Alan Woodland for major contributions to the development of duality theory and Thomas Rutherford for developing and implementing the complementarity formulation of general equilibrium models. In doing so, Rutherford simplified and standardized applied general-equilibrium analysis, allowing economists to concentrate on economics and policy analysis rather than on coding. The views expressed herein are those of the author and do not necessarily reflect the views of the National Bureau of Economic Research.

NBER working papers are circulated for discussion and comment purposes. They have not been peer-reviewed or been subject to the review by the NBER Board of Directors that accompanies official NBER publications.

(C) 2020 by James R. Markusen. All rights reserved. Short sections of text, not to exceed two paragraphs, may be quoted without explicit permission provided that full credit, including (C) notice, is given to the source. 
Global Comparatives Statics in General Equilibrium: Model Building from Theoretical Foundations James R. Markusen

NBER Working Paper No. 27219

May 2020

JEL No. D50,D58,F10

\begin{abstract}
$\underline{\text { ABSTRACT }}$
International trade economists made seminal contributions to general equilibrium theory, moving away from an emphasis on existence of equilibrium to algebraic formulations which enabled us to characterize key relationships between parameters and variables, such as that between tariffs and domestic factor prices and welfare. But the analysis remained limited in value for policy evaluation: the analysis was local, it provided only qualitative results, it was limited to very small models, and strictly interior solutions had to be assumed. The contribution of this paper is pedagogic and methodological, providing a primer for those wishing to do or teach generalequilibrium counterfactuals on (for example) structural models. I show how the tools from early local comparative statics analyses can be generalized via the use of Shepard's lemma, duality, complementarity and the Karush-Kuhn-Tucker theorem into a global, quantitative analysis of large changes in high-dimension models which also allows for regime changes and corner solutions. I then show how the resulting non-linear complementarity problem directly translates into a numerical model using GAMS (general algebraic modeling system).
\end{abstract}

James R. Markusen

Department of Economics

University of Colorado

Boulder, CO 80309-0256

and NBER

james.markusen@ colorado.edu 


\section{Introduction}

Simulation analysis of general equilibrium models used to be the territory of applied general-equilibrium modelers (also called computable general equilibrium) and members of this group were largely disjoint from international trade theorists and indeed empiricists using the tool kit of econometrics. I think it is fair to say that there was even some hostility among these groups. I regret not keeping some of the referees' reports on my early papers using numerical simulation as a theory tool in models far too complex for traditional paper-and-pencil analytical methods. But reading journals and attending conferences today makes it clear that, slowly but surely, simulation analysis has moved into the mainstream of international economics and other fields. Yet we lack a standard approach or template for formulating general-equilibrium models and, in my view, this has led some researchers to proceed on an ad hoc basis that does not allow transparency and verifiability (e.g., is the model correctly computing general-equilibrium comparative statics).

The purpose of this paper is to provide such a template, and to show how it easily translates into a computable numerical simulation model. As such, the paper is pedagogic and methodological. It makes no claim to offer original theoretical insights or results, but rather shows how familiar existing tools and well-known mathematical results combine to produce a simple, clear and consistent modeling framework. But first, a little history of thought about how we got here.

International trade economists' early contributions in formalizing our basic generalequilibrium model were a seminal contribution that reworked how we think about general equilibrium (GE). Early articles such as Jones $(1956,1965,1967)$ remained standard readings for graduate students for decades. Jones moved us away from focusing on issues of existence, uniqueness and stability of equilibrium to a more useful concentration on the actual properties of GE that we might be interested in as applied microeconomists in fields like international trade and public economics. How does, for example, a trade tariff affect the internal distribution of income in an economy? GE analysis focusing on existence of equilibrium and fixed-point algorithms is of little practical value for applied questions.

That having been said, the theoretical analysis of GE was paralleled by the development of applied general equilibrium analysis (AGE; also called computable general equilibrium). This was initiated by the algorithm of Scarf (1967) with the first large-scale implementations by Shoven and Whalley $(1973,1974)$. This algorithm and its refinements did use an iterative fixedpoint procedure to solve complex high-dimension models. But there were a number of inherent limitations in this approach and eventually AGE analysis went in another direction that was closer to the intellectual foundations of analytical trade theory.

One particularly important development by Jones was to provide early versions of what we would now call duality analysis. I will have more to say on this below, but basically it moved us from looking at production and utility functions to using cost functions which embody optimizing behavior at the level of firms and households. Then a general-equilibrium model can be built up, embodying the optimal choices for individual agents in the equations and inequalities of the model. This methodology for modeling GE is essentially what Jones was doing with his 
local comparative statics’ analysis in his seminal 1965 JPE paper.

These contributions to general equilibrium modeling were pathbreaking and remain important today. But there are of course limitations to the usefulness of the approach. Without in any way disparaging the importance of analytical contributions, some of these are as follows. First, the analysis is local and cannot easily be extended to large changes. Second, the results are qualitative, giving signs buy not magnitudes of effects in comparative-statics experiments. Third, the techniques cannot give even sign predictions past very simple cases such as a twogood, two-factor economy. Fourth, the comparative-statics methods cannot easily handle corner solutions in which parameter changes lead countries to change the set of goods they actual produce, switch technologies used to produce some goods, or cause changes in which trade links are active and inactive.

The purpose of my paper is to indicate how local analysis can be extended to a global analysis, which allows for the quantitative evaluation of large parameter changes and permits changes in trade and production specialization patterns (e.g., which production sectors and which trade links are active or inactive). I will show how this global analysis is rigorously built up from several key results from mathematics and economic theory. These generalizations are hugely important in the evaluation of large policy changes such as BREXIT, or economic shocks such as covid-19 where qualitative local analyses of small-dimension models are of no practical value.

In Jones’ seminal 1965 paper, he considers a two-good, two-factor economy facing (initially) fixed commodity prices. Let us focus on this simple case so that we have a smooth continuity between his analysis and that in the present paper.

\section{2. $\quad$ From local to global analysis}

Let $X$ and $Y$ be two goods with fixed world prices $p_{x}$ and $p_{y}$. There are two factors of production in fixed supply, denoted $L$ and $K$ with prices $w$ and $r$ respectively. Let $a_{I J}$ denote the optimal, or cost minimizing, amount of factor $i$ needed to produce one unit of good $j$. Cost minimization implies that the $a_{I J}$ are themselves functions of $w$ and $r$.

In a simple case with fixed world prices and fixed factor endowments, production is determined independently of demand. General equilibrium can be described by just four equations in four unknowns assuming that there is an interior solution in which both goods are produced (non-specialization). The four unknowns are $X, Y, w$, and $r$. Two equations are the competitive zero-profit conditions for $X$ and $Y$ : unit cost equals price. Henceforth, we will just refer to these equations (later weak inequalities) as pricing equations. The second two equations require that the demands for capital and labor from the $X$ and $Y$ sectors sum up to total factor endowments, henceforth called market-clearing equations. These four are given by

$$
\begin{aligned}
& a_{L X} w+a_{K X} r=p_{x} \\
& a_{L Y} w+a_{K Y} r=p_{y}
\end{aligned}
$$$$
\text { pricing equations }
$$ 


$$
\begin{aligned}
& L=a_{L X} X+a_{L Y} Y \\
& K=a_{K X} X+a_{K Y} Y
\end{aligned}
$$

These four equations illustrate nicely the duality between prices and quantities, and become the basic starting point for Jones' analysis in the 1965 paper and others to follow. This duality structure also illustrates why it is that if the Stolper-Samuelson theorem is valid then the Rybczynski theorem must be as well. The former is the effect of exogenous commodity price changes on the endogenous factor prices, and the latter is the effect of changes in the exogenous endowments on the endogenous commodity outputs, holding commodity prices constant.

I noted above the limitations of this approach for tasks such as the economy-wide evaluation of large policy changes or shocks. The analysis is local, qualitative (signs of derivatives, not magnitudes), limited to small-dimension models, and generally limited to interior solutions.

These limitations of the traditional comparative-statics approach thus calls for a broader and more comprehensive method for formulating and solving general-equilibrium models. This is the task to which we now turn. But it will be clear that the Jones approach is nevertheless the foundation of new techniques and that the latter are not a radical departure from the older tradition.

We begin by drawing on traditions that were partly implicit in Jones’ work, and developed further later on in books explicitly focusing on duality such as Takayama and Woodland (1980), Woodland (1980, 1982) and Dixit and Norman (1980). The trick is to first move from production and utility functions to cost functions, with those cost functions embodying not just technologies but also the optimizing behavior of individual firms and households. These can be termed 'value functions': the endogenous choices of inputs and outputs by firms and households are solved for by standard optimization methods and then inserted back into cost equations to get the minimum cost of producing goods or utility as a function of exogenous prices only.

In our 2x2 case outlined above, we can derive four value functions by standard optimization methods which use the Karush-Kuhn-Tucker theorem as the underlying methodology (Karush, 1939; Kuhn and Tucker, 1951).. Making the usual assumption that production and utility exhibit constant returns to scale, unit cost and expenditure functions depend only on prices and not on output levels. These four are given as follows.

$$
\begin{aligned}
& c_{x}=c_{x}(w, r), \quad c_{y}=c_{y}(w, r) \quad \text { unit cost functions for } X \text { and } Y \\
& e=e\left(p_{x}, p_{y}\right) \quad \text { unit cost (expenditure) function } \\
& v=v\left(p_{x}, p_{y}, I\right) \quad \text { indirect utility function }
\end{aligned}
$$

The next crucial step is also provided by theory. Shephard's lemma, which follows from the envelope theorem, implies that the partial derivatives of these value functions give us 
the optimal choices of inputs and outputs given prices for goods and factors.

$$
\begin{array}{ll}
\frac{\partial c_{x}}{\partial w}=a_{L X} & \text { optimal amount of labor per unit of } X \text { output } \\
\frac{\partial c_{x}}{\partial r}=a_{K X} & \text { optimal amount of capital per unit of } X \text { output } \\
\frac{\partial e}{\partial p_{x}}=h_{X} & \text { consumer's demand for } X \text { per unit of utility (Hicksian) } \\
-\frac{\partial v}{\partial p_{x}} / \frac{\partial v}{\partial I}=d_{X} & \text { consumer demand for } X \text { per unit of income (Marshallian) }
\end{array}
$$

with corresponding equations for the sector $Y$ cost function and $Y$ demand. The last of the results shown is generally referred to as Roy's identity. Though it is obvious and well-known to most readers, note that the expenditure function is just a cost function under a different name: it gives the minimum cost at existing commodity prices needed to purchase one unit of utility.

There is one final property that we don't really need, but it will show how the more modern approach matches with Jones' contributions in a natural way. If the production and utility functions are characterized by constant returns to scale, then these value functions are also homogeneous of degree one, and they can be written as the sum of their partial derivatives each times the value of the input variable. For example, the cost function for $X$ can be written as:

$$
c_{x}(w, r)=\frac{\partial c_{x}}{\partial w} w+\frac{\partial c_{x}}{\partial r} r=a_{L X} w+a_{K X} r
$$

This is, of course, Jones' equation for the unit cost of producing good $X$.

The more modern approach to AGE modeling uses these tools as the building blocks for a global analysis. In addition to having the ability to evaluate large changes such as large-scale trade liberalization or tax reform, the newer approach permits corner solutions in which some production activities or trade links can switch from inactive to active and vice versa as a consequence of parameter changes. This requires us to detour into complementarity, a concept that follows directly from the Karush-Kuhn-Tucker (KKT) theorem.

\section{General equilibrium and complementarity}

Equilibrium is modeled as a set of weak inequalities, each with a complementary nonnegative (lower bounded) variable. Pricing inequalities such as those above are written as unit cost greater than or equal to price, with output of that activity (industry, trade flow, etc.) being the complementary variable. If the activity is unprofitable in equilibrium (strict inequality), it is not used and the complementary output variable is zero. If supply exceeds demand in equilibrium, the price is zero (it is a free good). Note that pricing inequalities have quantities as complementary variables, quantity (market clearing) inequalities have prices as complementary 
variables. The KKT theorem introduces added "slack" or complementary variables so that the weak inequalities become equations, which then allows solver algorithms to use iterative methods to solve the system of equations.

Market clearing inequalities such as (3) and (4) above (strict equalities in Jones’ model) are strictly speaking not KKT optimization conditions, but rather equilibrium conditions. Yet they can be handled in a way closely equivalent to KKT conditions. A market clearing inequality is written as supply greater than or equal to demand, with price being the complementary variable. For example, if the supply of pollution permits exceeds demand in equilibrium, the market price of a permit is zero.

The strong microeconomic foundations of duality and complementarity via the KKT theorem eventually led modelers to move away from fixed point methods for constructing and solving GE models to instead treating general equilibrium as a sequence of complementarity problems at the level of industries and households. Notable in this development were contributions by Mathiesen (1985) and Rutherford (1995). Rutherford's MPS/GE (mathematical programming for general equilibrium) allowed for the easy calibration and implementation of the complementarity approach. An early example of this is Harrison, Wooton, Rutherford (1989).

Now let us look at an actual implementation using the Jones' model. We stick with our two-good, two-factor model from above, but introduce a representative consumer to make it a closed economy model. First, we use the Marshallian demand formulation for the consumer. A seven inequality, seven variable model is as follows. There are two pricing inequalities, four market-clearing inequalities, and one income-balance equation.

\begin{tabular}{llll}
\hline$a_{L X} w+a_{K X} r \geq p_{x}$ & $\perp$ & $X$ & \\
$a_{L Y} w+a_{K Y} r \geq p_{y}$ & $\perp$ & $Y$ & pricing (zero-profit) inequalities \\
\hline$L \geq a_{L X} X+a_{L Y} Y$ & $\perp$ & $w$ & \\
$K \geq a_{K X} X+a_{K Y} Y$ & $\perp$ & $r$ & \\
$X \geq d_{x} I$ & $\perp$ & $p_{x}$ & \\
$Y \geq d_{y} I$ & $\perp$ & $p_{y}$ & \\
\hline$I=w L+r K$ & & & \\
\hline
\end{tabular}

Note that the first four weak inequalities are the Jones' equations from above: if the prices of $X$ and $Y$ are fixed by world markets (small open economy assumption), then these four can be solved on their own for the four complementary variables. 
After solving this model, the utility and price index for the representative consumer can be calculated. All alternative procedure, especially useful when there are multiple household types or countries is to use a Hicksian formulation. This treats utility as if it were a produced good: commodities are inputs into the production of a utility good, and the expenditure function is the minimum cost of producing one unit. There is also a (virtual) market for the utility good, with a market clearing equation and complementary variable: the price of a unit of utility. This is what we generally label as the consumer price index. This model is a little more complicated, but it computes utility and the price index for each household type or country as part of the solution. Denote $U$ as utility and $p_{u}$ as the price index. Our extended Hicksian model is given by nine weak inequalities in nine unknowns.

\begin{tabular}{llll}
\hline$a_{L X} w+a_{K X} r \geq p_{x}$ & $\perp$ & $X$ & \\
$a_{L Y} w+a_{K Y} r \geq p_{y}$ & $\perp$ & $Y$ & pricing (zero profit) inequalities \\
$h_{x} p_{x}+h_{y} p_{y} \geq p_{u}$ & $\perp$ & $U$ & \\
\hline$L \geq a_{L X} X+a_{L Y} Y$ & $\perp$ & $w$ & \\
$K \geq a_{K X} X+a_{K Y} Y$ & $\perp$ & $r$ & \\
$X \geq h_{x} U$ & $\perp$ & $p_{x}$ & market-clearing inequalities \\
$Y \geq h_{y} U$ & $\perp$ & $p_{y}$ & \\
$U \geq I / p_{u}$ & $\perp$ & $p_{u}$ \\
\hline$I=w L+r K$ & & & \\
\hline
\end{tabular}

Following earlier comments, the strength of this approach is that it computes equilibria for large changes in parameters and high-dimension models, it will give quantitative results, and it allows for corner solutions in which some variables switch from slack (equal to zero) to positive or vice versa. However, there are also some limitations. First, an implementation requires explicit functional forms for production and utility. Furthermore, quantitative analysis requires that numerical parameter values must be chosen for those functional forms. I and others using numerical models as a theory tool acknowledge this tradeoff, but note that insisting on analytical models only often requires the modeler to simplify the model so much that the interesting parts of the problem are discarded. ${ }^{1}$

\footnotetext{
${ }^{1}$ The complementarity approach is adaptable to very complex economies. For models with increasing returns to scale, imperfect competition, endogenous markups, and endogenous firm location decisions, see Markusen (2002, paperback 2004). Examples of these techniques used in very large
} 


\section{A numerical implementation}

We can now look at an actual implementation of our model, and stick with the Marshallian formulation since it is a bit simpler. We use Cobb-Douglas functions for the three activities so that it is simple and straightforward for readers to see exactly where the equations and inequalities are coming from. There is no attempt to base parameter values on any realworld equivalents, they are chosen to provide maximum transparency. Goods in the utility function get equal shares of 0.5 . The representative consumer's utility function and the implied expenditure function are given as follows.

$$
U(X, Y)=2 * X^{0.5} Y^{0.5} \quad=>\quad e\left(p_{x}, p_{y}\right)=p_{x}{ }^{0.5} p_{y}{ }^{0.5}
$$

Using a textbook Lagrangean optimization formulation of KKT, Marshallian and Hicksian unit demand functions are as follows.

$$
d_{x}=0.5 / p_{x} \quad d_{y}=0.5 / p_{y} \quad h_{x}=0.5 * p_{x}^{-0.5} p_{y}{ }^{0.5} \quad h_{y}=0.5 * p_{x}{ }^{0.5} p_{y}{ }^{-0.5}
$$

$\mathrm{X}$ is (arbitrarily) capital intensive: a capital share of 0.75 , a labor share of 0.25 .

$$
\begin{aligned}
& c_{x}(w, r)=w^{0.25} r^{0.75} \\
& a_{L X}=0.25 * w^{-0.75} r^{0.75}=0.25 *(r / w)^{0.75} \\
& a_{K X}=0.75 * w^{0.25} r^{-0.25}=0.75 *(w / r)^{0.25}
\end{aligned}
$$

$\mathrm{Y}$ is labor intensive with the opposite ordering of shares.

$$
\begin{aligned}
& c_{y}(w, r)=w^{0.75} r^{0.25} \\
& a_{L Y}=0.75 * w^{-0.25} r^{0.25}=0.75 *(r / w)^{0.25} \\
& a_{K Y}=0.25 * w^{0.75} r^{-0.75}=0.25 *(w / r)^{0.75}
\end{aligned}
$$

Let $\bar{L}(L B A R)$ and $\bar{K}(K B A R)$ denote economy's fixed endowments of labor and capital. We now have a complete numerical model with only two parameters to be chosen which are the endowment quantities. We do not need to expand the $X$ and $Y$ cost functions using the homogeneity property discussed above, we can just use the unit cost functions. Here then is the implemented model.

$$
w^{0.25} r^{0.75} \geq p_{x} \quad \perp \quad X
$$

theory models, see Markusen and Venables (2007) (29,000 non-linear inequalities and unknowns) and Markusen (2013) (36,000 non-linear inequalities and unknowns). 


$$
\begin{array}{lcc}
w^{0.75} r^{0.25} \geq p_{y} & \perp & Y \\
L B A R \geq 0.25 *(r / w)^{0.75} X+0.75 *(r / w)^{0.25} Y & \perp & w \\
K B A R \geq 0.75 *(w / r)^{0.25} X+0.25 *(w / r)^{0.75} Y & \perp & r \\
X \geq 0.5 I / p_{x} & \perp & p_{x} \\
Y \geq 0.5 I / p_{y} & \perp & p_{y} \\
I=w * L B A R+r * K B A R & \perp & I
\end{array}
$$

While any values of $L B A R$ and $K B A R$ will produce a solution, it is a good practice to start with a calibrated solution as a check on the modeler's consistency. This is generally referred to as the "replication check": running the model should yield the initial calibrated values as a solution, otherwise something is wrong. If we choose $L B A R=100$ and $K B A R=100$, then due to the symmetry in production and consumption shares, we should get a solution in which $X=Y$ $=100, I=200$, and all prices equal one.

One of the principal objectives of this paper is pedagogic: demonstrate how to move from a traditional algebraic model used for local comparative-statics experiments to more robust and useful global comparative statics. According, I will show an actual numerical model. The code is available from me on request. I hope that by showing the code, I can help aspiring modelers to get a big head start in seeing that global general-equilibrium analysis is relatively easy to do.

By far the preferred software for implementing and solving this model is GAMS (general algebraic modeling system). GAMS is an algebraic language and thus it is intuitive and relatively easy to master. Equations are written exactly as they are done here in the text, and there are no weird symbols or characters that need to be memorized in order to do straightforward things. In addition, the solvers in GAMS are constructed on the basis of theory (KKT), particularly the MCP (mixed complementary problem) solver called PATH which uses a generalization of Newton's method.

A quick note: as a consequence of Walras Law, there is an indeterminacy of the price level in the model, so one price is chosen as numeraire and fixed at one. The complementary equation is then automatically dropped by GAMS from the model. The price of good $Y\left(p_{y}\right)$ is chosen as numeraire and its price fixed at one. ${ }^{2}$

${ }^{2}$ In GAMS, PY.FX denotes fixing the variable PY; then the equation complementary to that variable is automatically dropped from the model. PY.L is the notation for setting the initial value or level of variable PY, but that variable is not held fixed. Setting initial values of variables is important for the solver to solve the model and solve efficiently in all non-linear problems. 
\$TITLE: IJET model, James Markusen, University of Colorado, Boulder

* two goods, two factors, one consumer, closed economy

* Marshallian approach

PARAMETERS

LBAR labor endowment

KBAR capital endowment;

LBAR $=100 ;$

KBAR $=100 ;$

NONNEGATIVE VARIABLES

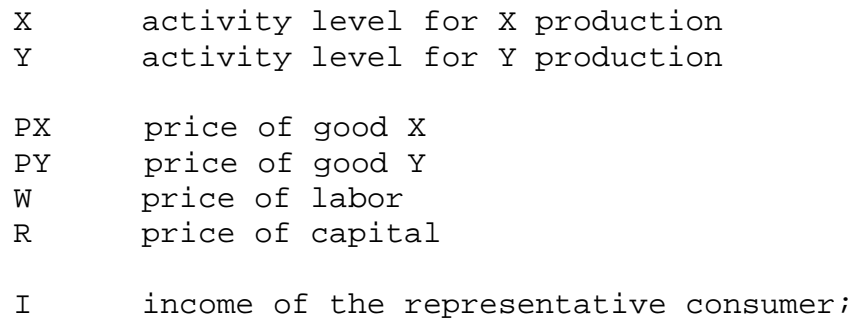




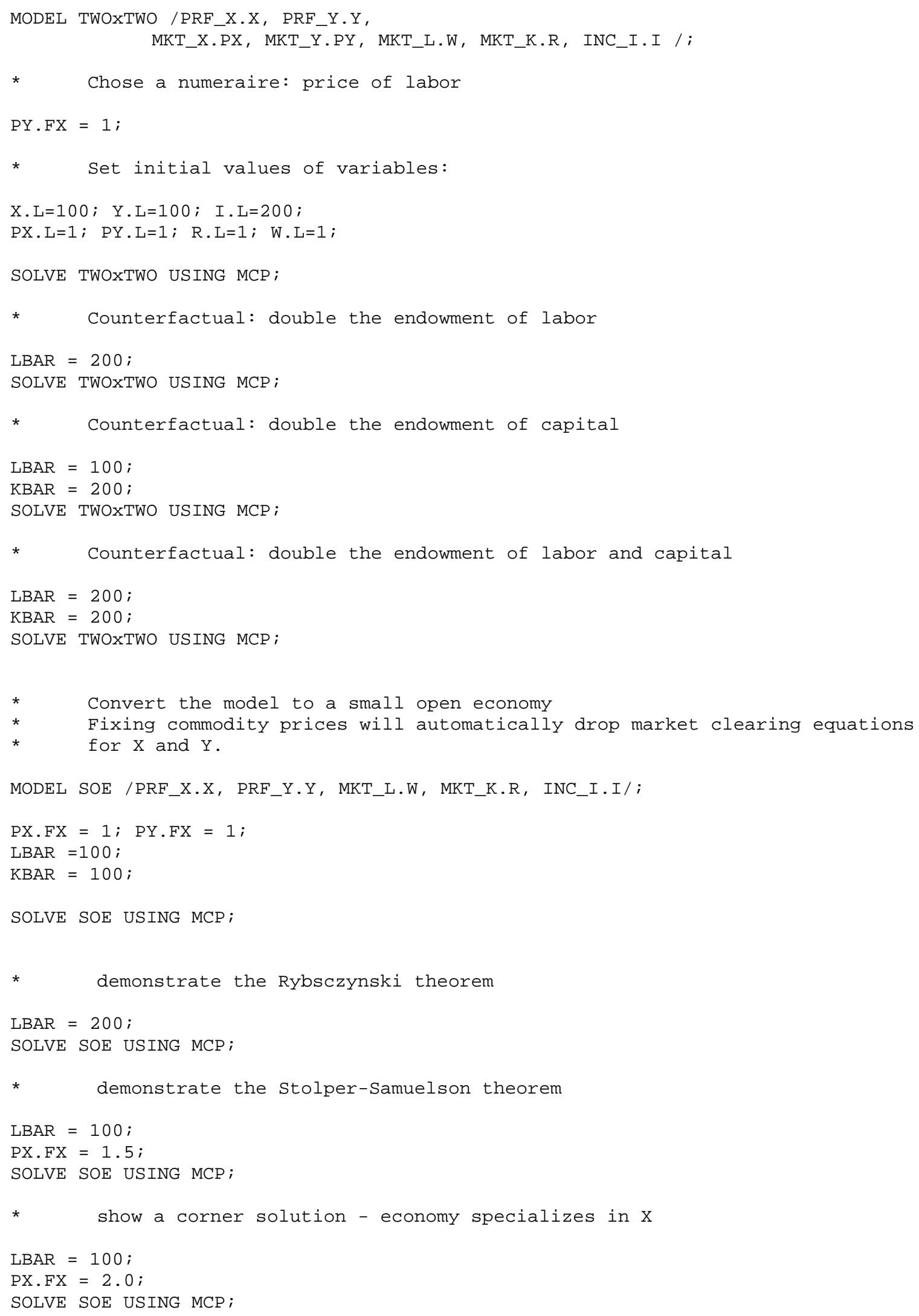


Tables 1 and 2 show results for eight runs of the model. Table 1 gives results for the closed economy, Table 2 for a small open economy. The first column in each Table is the calibrated benchmark replication. In Table 1, the second column gives results for doubling the labor endowment to LBAR $=200$. Production shifts toward the labor-intensive good $Y$, the relative price of $Y$ falls, labor's wage falls relative to both commodity prices and the return to capital rises. This second column of Table 1 also illustrates what we could call aggregate diminishing returns. Doubling the endowment of one factor, which is fifty percent of income in the benchmark, increases total production of $X$ and $Y$ by less than fifty percent evaluated at initial prices. Welfare (not shown) increases from 200 in the benchmark to 283.

Column three of Table 1 gives a cautionary note about interpreting price changes, because I have seen authors make some misleading or simply wrong statements about this. Column three reverses the experiment of column 2, doubling the endowment of capital instead of labor. Because of the symmetry of $X$ and $Y$ in demand and because factor intensities are mirror imagines of each other in $X$ and $Y$, the changes in the outputs of the two goods are the mirror imagines of those in column 2. But the price changes and income look quite different. This is entirely due to the choice of numeraire: the relative prices of $X$ and $Y$ and $L$ and $K$ are inverses of column 2. Welfare is the same in both columns (equal to indirect utility: $p_{x}{ }^{-0.5} p_{y}{ }^{-0.5} I=283$ ). General equilibrium modelers need to take care to note how measures of income change are sensitive to the choice of numeraire, though welfare is not. Column 4 of Table 1 is a simple demonstration of the consequences of homogeneity of degree one in production and homothetic preferences. Doubling both factors of production just doubles both outputs and leaves all prices unchanged.

Table 2 is intended to be close to Jones' (1965) analysis and that of the standard Heckscher-Ohlin model. Commodity prices are fixed at one to represent a small open economy (endowments are returned to their original level). The first column is the benchmark replication. The second column doubles the endowment of labor, results contrasting to Table 1 where prices change. Holding commodity prices constant, column 2 of Table 2 illustrated the Rybczynski theory and Jones' magnification effect. Production of the labor intensive good more than doubles and the production of the capital intensive good shrinks. Unlike doubling labor in the closed economy, there are no aggregate diminishing returns: the added labor is absorbed without a fall in $w$ by changing the composition of production.

Column 3 of Table 2 returns labor endowment to its original value and raises the relative (world) price of $p_{\mathrm{x}}$ to 1.5 , a terms-of-trade improvement. $\quad X$ is capital intensive, and so the price increase results in the price of capital increasing by more than both commodity prices and the price of labor falls in terms of both commodity price. Regardless of consumption preferences, capital is better off and labor is worse off. This is the Stolper-Samuelson theorem.

I have included the last column of Table 2 to make another point about the limitations of local comparative statics that assumes an interior solution before and after a parameter change versus global analysis in a complementarity framework. If $p_{\mathrm{x}}$ is increased from its benchmark value of 1 to $p_{\mathrm{x}}=2$, the economy becomes specialized in $X$. Any further increase in $p_{\mathrm{x}}$ will continue to increase welfare, but it will have no effect on relative factor prices since all factors are employ in $X$. Stolper-Samuelson only works under the assumption of non-specialization. 


\section{Summary}

Trade economists made fundamental contributions to general equilibrium analysis by formulating models using the building blocks of what we now call duality techniques. These produced models which were far more useful for the analysis of practical questions of the type asked by trade and public-economics economists than earlier analyses focusing on existence, uniqueness, and stability of equilibria. Local comparative statics analysis is used to ask questions about changing factor endowments, changing technologies, changing world prices and changing trade and domestic taxes. This immensely improved our ability to understand such things as the relationship between world commodity prices and domestic income distribution.

Limitations remained of course. The analysis was for small changes only, results were qualitative (signs and some relative magnitudes) and the method was generally restricted to interior solutions only in which initially positive variables could not go to zero or vice versa. What this paper shows however, is that the use of duality tools such as converting production functions and utility functions to cost and expenditure functions paved the way for a more complete global analysis using complementarity built on the foundations of the Karush-KuhnTucker theorem. I show how key tools and theorems lead naturally to a formulation that allows large changes, yields quantitative results needed by policy makers, and allows corner solutions to emerge or disappear in response to changing parameters such as technologies, trade costs or tariffs.

The newer global analysis comes at some costs. Specific functional forms are needed and indeed specific parameter values for those functions. But specific functional forms are always needed if one wants quantitative results. In models with scale economies and imperfect competition, even qualitative results cannot be obtained without specific functional forms. Often parameters can be drawn from literature estimates or estimated econometrically as part of the analysis at hand. Sensitivity analysis can indicate which parameters have major or minor effects on the results. But global simulation analysis has indeed improved our ability to provide some answers to important public policy questions. 


\section{REFERENCES}

Dixit, Avinash and Victor Norman (1980), Theory of International Trade, Cambridge University Press.

Harrison, Glen W., Thomas F. Rutherford, and Ian Wooton (1989), “The Economic Impact of the European Community”, American Economic Review 79(2), 288-294.

Jones, Ronald W. (1956), “Factor Proportions and the Heckscher-Ohlin Theorem”, Review of Economic Studies 24, 1-10.

Jones, Ronald W. (1965), “The Structure of Simple General Equilibrium Models,” Journal of Political Economy 73, 557-572.

Jones, Ronald W. (1967), "International Capital Movements and the Theory of Tariffs and Trade,” Quarterly Journal of Economics 81, 1-38.

Karush, William (1939), Minima of Functions of Several Variables with Inequalities as Side Constraints, M.Sc. thesis, Department of Mathematics, University of Chicago.

Kuhn, Harold W. and Albert W. Tucker (1951), “Nonlinear Programming”, Proceedings of $2^{\text {nd }}$ Berkeley Symposium. Berkeley: University of California Press, 481-492.

Mathiesen, Lars (1985), “Computation of Economic Equilibria by a Sequence of Linear Complementarity Problems”, Mathematical Programming 23, 144-162.

Markusen, James R. (2002), Multinational Firms and the Theory of International Trade, Cambridge: MIT Press.

Markusen, James R. and Anthony J. Venables (2007), “Interacting Factor Endowments and Trade Costs: A Multi-Country, Multi-Good Approach to Trade Theory”, Journal of International Economics 73, 333-354.

Markusen, James R. (2013), "Expansion of Trade at the Extensive Margin: A General Gainsfrom-Trade Result and Illustrative Examples”, Journal of International Economics 88, 262-270.

Roy, René (1947), “La Distribution du Revenu Entre Les Divers Biens”, Econometrica 15(3): 205-225.

Rutherford, Thomas F. (1995), "Extensions of GAMS for complementarity problems arising in applied economic analysis”, Journal of Economic Dynamics and Control 19(8), 12991324.

Scarf, Herbert (1967), “Approximation of Fixed Points of a Continuous Mapping”, SIAM Journal of Applied Mathematics 15(5), 1328-1343. 
Shepard, Ronald (1953), The Theory of Cost and Production Functions, Princeton: Princeton University Press.

Shoven, John B. and John Whalley (1973), "General Equilibrium with Taxes: Computational Procedure and an Existence Proof”, Review of Economic Studies 40(4), 475-489.

Shoven, John B. and John Whalley (1974), "Computation of Competitive Equilibrium on International Markets with Tariffs”, Journal of International Economics 4(4), 341-354.

Takayama, T. and Alan D. Woodland (1970), "Equivalence of Price and Quantity Formulations of Spatial Equilibrium: Purified Duality in Quadratic and Concave Programming”, Econometrica 38(6), 889-906.

Woodland, Alan D. (1980), “Direct and Indirect Trade Utility Functions”, Review of Economic Studies 47(5), 907-926,

Woodland Alan D. (1982), International Trade and Resource Allocation, Amsterdam: North Holland. 
Table 1: Closed economy results

$\begin{array}{lrrrr}\text { Variable } & \text { Benchmark } & \begin{array}{c}\text { Double labor } \\ \text { endowment }\end{array} & \begin{array}{l}\text { Double capital } \\ \text { endowment }\end{array} & \begin{array}{l}\text { Double both labor } \\ \text { and capital }\end{array} \\ \text { X } & 100.00 & 118.92 & 168.18 & 200.00 \\ \text { Y } & 100.00 & 168.18 & 118.92 & 200.00 \\ \text { PX } & 1.00 & 1.41 & 0.71 & 1.00 \\ \text { PY } & 1.00 & 1.00 & 1.00 & 1.00 \\ \text { W } & 1.00 & 0.84 & 1.19 & 1.00 \\ \text { R } & 1.00 & 1.68 & 0.59 & 1.00 \\ \text { I } & 200.00 & 336.36 & 237.84 & 400.00\end{array}$

Notes to Table 1: $\quad$ Column 2 illustrates aggregate diminishing returns

Column 3 illustrates need for care interpreting results dependent on numeraire

Column 4 illustrates homogeneity of the economy under constant returns in production and homothetic preferences

Table 2: Small open economy results

\begin{tabular}{|c|c|c|c|}
\hline Benchmark & $\begin{array}{l}\text { Double labor } \\
\text { endowment }\end{array}$ & $\begin{array}{l}\text { Increase price of } \\
\text { good X by } 50 \%\end{array}$ & $\begin{array}{l}\text { Increase price of } \\
\text { good X by } 100 \%\end{array}$ \\
\hline
\end{tabular}

Variable

$\begin{array}{lrrrr}\mathrm{X} & 100.00 & 50.00 & 156.50 & 175.48 \\ \mathrm{Y} & 100.00 & 250.00 & 30.62 & \\ \mathrm{PX} & 1.00 & 1.00 & 1.50 & 2.00 \\ \mathrm{PY} & 1.00 & 1.00 & 1.00 & 1.00 \\ \mathrm{~W} & 1.00 & 1.00 & 0.82 & 0.88 \\ \mathrm{R} & 1.00 & 1.00 & 1.84 & 2.63 \\ \mathrm{I} & 200.00 & 300.00 & 265.36 & 350.95\end{array}$

Notes to table 2: $\quad$ Column 2 illustrates the Rybczynski Theorem Column 3 illustrates the Stolper-Samuelson Theorem Column 4 illustrates the importance of not ruling out corner solutions (specialization) 